\title{
Analysis of Scientific Research in Selected Institutions in South Africa: A Bibliometric Study
}

\author{
Daisy Jacobs ${ }^{2}$ \\ Dept of Information Science, University of Pretoria, South Africa \\ daisy.jacobs@up.ac.za
}

Received: $29^{\text {th }}$ October 2005

Accepted: $6^{\text {th }}$ February 2006

\begin{abstract}
This paper reports the preliminary findings on South Africa's most productive authors, journals and research universities. The paper makes use of Scientometric techniques to assess the quantity and quality of science research papers published by researchers in various journals. The results show that four of the most cited authors represent $40.80 \%$ of the total count. The citations per paper for these authors are Bilic N (16.40), Michael JP (6.36), Sacht C (6.00), and Marques HM (4.60). The majority of citations are found within Chemistry (37.0\%), followed by Physics (26.0\%), Medicine (7.40\%) and Biology (7.40\%). Analysis of 18 journals indexed in the Journal Citation Report (JCR), revealed that only the South African Journal of Geology had an impact factor above one. The journal with the largest numbers of original papers was the South African Journal of Science with 89 articles and 1397 total citations in 2003. Statistical analysis, with Pearson's correlation coefficient ( $p$-value <0.05), indicated significant correlation between journal productivity and citation frequency, as well as between citation frequency and immediacy index.
\end{abstract}

Key words: Scientific Research; Bibliometrics; South Africa; Institutions

\section{Introduction}

The qualitative and quantitative evaluation of scientific production is a common need in the entire research world. Scientists searching references for study, committees awarding grants, managers evaluating candidates and students reading a paper are all determined through the evaluation of their scientific research output (Cole. S, Cole, \& Simon, 198I). Bibliometrics is a quantitative assessment of man's cultural progress, including science and technology as may be revealed through bibliographic data. Bibliographic data are those that can be collected, derived or deciphered from different parameters as can be assigned to a document (Sen., Subir \& Chatterjee, 1990).

Bibliometrics offers a powerful set of methods and measures for studying the structure and process of scholarly communication. For a long time bibliometrics based on the number of publications have been used as indicators to evaluate the research capacity and competitiveness of a university (Moed et. Al., 1985). In the quantitative approaches of evaluation, numbers of publications, citations and highly cited authors and their papers are often considered as science indicators. According to Egge, Rousseau \& Van Hoydoonk (2000), different methods applied in counting methods have their problems. But in most cases, these problems and short comings are overlooked or neglected. One of the bestknown bibliometric approaches, namely, citation analysis, has become more sophisticated, and the advent of networked information technologies has led to quantitative and qualitative advances in other bibliometric methods (Christine, Borgman \& Jonathan, 2002). Bibliometrics thus enables researchers/librarians to contribute to detailed analysis of research activities within their institutions. This is achieved by searching bibliographic databases and subsequent ranking of individual papers retrieved from scientific sub fields, followed by citation analysis including co-citation analysis and bibliographic coupling (Osareh, 1996)

This paper used ISI's Essential Science Indicators database to evaluate the research performance of the five researchoriented universities from 1994 to 2003 with the number of papers, citations, the average citations per paper, the number of highly cited papers and the number of highly cited authors. The indicators obtained were used to analyse and evaluate the strengths of the universities and the highly cited authors and highly cited South African journals.

The structural approach used in this paper identifies published works and then reviews citation patterns in the literature. This paper further reveals patterns relating to publishing activity by year for individual as well as total number of publications, comparative analysis among different fields of study, and most influential authors and cited works. It has also tried to review and analyze journals according to the impact factor and immediacy index. The study endeavoured to analyze seven main disciplinary fields within medicine, natural \& physical sciences and technology. The analysis is commonly shown as time series consisting of running 5 -year periods.

I. The original version of this paper was presented at the I0th International Conference of the International Society of Scientometrics and Informetrics, 24th-28th July 2005, Karolinska Institute, Stockholm, Sweden.

2. Daisy Jacobs, $\mathrm{PhD}$, is a Senior Lecturer in the Department of Information Science, University of Pretoria 
The objectives of this study were:

- To identify highly productive authors and their contributions.

- To evaluate and identify top South African journals and their performance based on productivity

- To investigate whether there is a significant relationship between productivity, citation frequency, impact factor and cited half-life of South Africa's top journals

- To compare the development of South African relative citation impact for the most productive institutions.

\section{Methodology}

The data presented in this paper consists of scientific articles published in journals processed on the Institute of Scienctific Information (ISI) databases such as Science Citation Index (SCl), Social Sciences Citation Index (SSCl) and South African Studies Databases. The South African Studies Databases consists of 15 different databases providing access to the great majority of documents published in and about South Africa. Each of the databases provide access to over 938400 records, touching both science and medicine.

All papers recorded in the annual volumes of the Science Citation Index $(\mathrm{SCl})$ of the Institute for Scientific Information (ISI), as articles, notes or reviews were taken into consideration for the period of 1994-2003. For each paper, the reference data was retrieved from ISI's Web of Science resulting in uniform format and journal abbreviations. Data were collected for the seven disciplines of Physics, chemistry, Botany, Zoology, Microbiology and Biochemistry Engineering and Clinical medicine.

The data for citation frequency, journal impact factor and cited half life were obtained from the Journal Citation Reports (JCR), an ISI product published annually in two editions (science and social sciences) in print and on CD-ROM. To determine the impact factor, a common assumption was adopted; that is, the impact can be measured by the number of times a publication is cited from a standard set of journals over a fixed time span. This is the number of citations from the ISI databases in a year to all papers in the journal for the two previous years, divided by the number of those papers. According to Wilson and Pittman (2000), the yearly impact factors for some 7000 journals are published in ISI's Journal Citation Reports. Thus the JCR provides a systematic and objective indicator of the relative importance of scholarly journals and the papers within them. With the assumption that the impact of any paper in a journal is well-estimated by the 'average of paper', that is its journal impact factor which can be obtained from the annual issue of JCR. It further gave a measure of the overall quality of the publications on science for each year by the mean of each set of publications. Thus the impact factors of Citations were verified according to ISI databases for the period of 1994-2003. This process enabled identification of highly cited journals, highly cited field and highly cited institutions. The impact analysis is restricted to citations received from ISI indexed research papers. The relative citation scores are based on five-year citation windows; self-citations have been excluded. In the National Science Indicator (NSI) database, one of the standard indicators is a 5year citations indicator using overlapping periods.

The data were analyzed using Microsoft Excel and the SPSS statistical software package. Pearson's correlation coefficient was used to investigate the association among productivity, citation frequency, and impact factor and cited halflife. A one-tailed test $t$-test was used and it was carried out at the $95 \%$ and $99 \%$ level of confidence.

\section{Findings and discussions}

This section reports on most cited authors and works, evaluation of the performance of South African journals and a relative comparison of the research oriented universities in South Africa

\subsection{Most cited authors and works}

Citation analysis is a widely used tool in academia to assess the impact of scholarly output and trends in scholarship in a particular field by tracking references in the footnotes and bibliography of academic articles. Citation analysis is considered to be more objective than qualitative judgements, which are prone to bias and favouritism. It is therefore widely used to rate academic journals, departments and individual researchers for external assessments, including grant proposals (Fazel \& Danesh, 1995).

The major area of bibliometric research uses various methods of citation analysis in order to establish relationships between authors and their work. As can be seen in Table I, there were 27 authors during 2000-2003, each with at least 2 papers and 2 citations. Despite the fact that there were many South African scientists who had published during the given period, only those authors who had been cited above the threshold (greater than or equal to 0.25 cited per paper) were selected, 27 authors in all. The total number of papers produced per author during the given period ranged between 2 and 34 respectively. Similarly, the number of citations per paper varied from 2 to 210. 
Table I Authors ranked according to citation per paper

\begin{tabular}{|c|c|c|c|c|c|c|c|c|c|}
\hline Rank & Authors & No. Paper & No. Cited & Cited per paper & Rank & Authors & No. Paper & No.Cited & Cited per paper \\
\hline I & Bilic N & 5 & 82 & 16.4 & 15 & Carlton-L & 9 & 23 & 2.56 \\
\hline 2 & Michael JP & 33 & 210 & 6.36 & 16 & Myers TG & 7 & 16 & 2.30 \\
\hline 3 & Sacht C & 4 & 24 & 6.00 & 17 & Munyaneza-F & 2 & 4 & 2.00 \\
\hline 4 & Marques-HM & 27 & 123 & 4.60 & 18 & Chinake-CR & 2 & 4 & 2.00 \\
\hline 5 & Gutzmer J & 16 & 72 & 4.50 & 19 & Koch-KR & 15 & 28 & 1.90 \\
\hline 6 & Truesdale WW & 2 & 9 & 4.50 & 20 & Cortie-MB & 14 & 25 & 1.79 \\
\hline 7 & Mace RL & 8 & 35 & 4.40 & 21 & Jacobs D & 4 & 6 & 1.50 \\
\hline 8 & Smith VR & 16 & 68 & 4.25 & 22 & Darkwa & 19 & 28 & 1.47 \\
\hline 9 & Bandoli-G & 5 & 21 & 4.20 & 23 & Laing $M$ & 15 & 15 & 1.00 \\
\hline 10 & McKenzie If & 27 & 99 & 3.70 & 24 & Davidowitz B & 3 & 3 & 1.00 \\
\hline 11 & Raubenheimer HG & 34 & 118 & 3.50 & 25 & Dominguez-CA & 8 & 6 & 0.75 \\
\hline 12 & Rautenbach M & 8 & 23 & 2.90 & 26 & Engelbrecht-GD & 5 & 2 & 0.40 \\
\hline 13 & Zunckel M & 4 & 11 & 2.75 & 27 & Lues JF & 8 & 2 & 0.25 \\
\hline 14 & Burgess IJ & 7 & 19 & 2.71 & & & & & \\
\hline
\end{tabular}

Table I shows the number of papers, citations, and average citations per paper from 1994 to 2003 for the most cited authors. The four leading authors, noted to have produced more than 25 papers during the period of study, in order of ranking, were Raubenheimer HG (34), Michael JP (33), Marques HM (27) and McKenzie IF (27). Analysis of authors' performance from citations received per paper showed that four of the most cited authors represented $40.80 \%$ of the total. These were Bilic N (16.40), Michael JP (6.36), Sacht C (6.00), and Marques-HM (4.60): Gutzmer J, Truesdale WW and Mace RL, received 4.50, 4.50 and 4.40 citations per paper respectively.

From the total number of citations (1076) received, 572 (53.20\%) citations were found within Chemistry; 267 (24.80\%) in Physics; 72 (7.0\%) in Geology and 68 (6.30\%) in Plant Science. All other departments account for below $5.00 \%$ of citations. Further analysis with regards to authors per department indicated that out of the top 27 authors noted, the majority was found within Chemistry (37.0\%), followed by Physics (26\%), Medicine (7.40\%) and Biology (7.40\%). The number of top selected authors from other departments accounted for $3.70 \%$ each.

Table 2 Distribution of publications according to subject field and institutions, 1994-2003

Field (participation \%)

\begin{tabular}{|c|c|c|c|c|c|c|c|c|}
\hline Institution & CLNIC & PLT\&ANM & BIO\&BICH & ENGIN & ENV\&ECO & CHEM & PHY & Total* \\
\hline UP & $560(\mid 4.55)$ & $1436(37.31)$ & $101(2.62)$ & $44 I(I I .46)$ & $377(9.80)$ & $332(8.63)$ & $602(15.64)$ & $3849(19.84)$ \\
\hline UCT & $1732(33.32)$ & $873(16.79)$ & $431(8.30)$ & $67 \mid(12.91)$ & $54 I(10.4 I)$ & $4 \mid I(7.9 \mid)$ & $539(10.37)$ & $5198(26.80)$ \\
\hline NATAL & $947(29.98)$ & $7 \mid 4(22.60)$ & $84(2.66)$ & $319(10.10)$ & $275(8.70)$ & $324(10.26)$ & $496(15.70)$ & $3159(16.28)$ \\
\hline STELL & $970(26.5 I)$ & $642(17.55)$ & $161(4.40)$ & $75 I(20.52)$ & $32 \mathrm{I}(8.77)$ & $309(8.44)$ & $505(\mid 3.80)$ & $3659(18.86)$ \\
\hline WITS & $1516(42.90)$ & $379(10.72)$ & $158(4.50)$ & $338(9.56)$ & $232(6.56)$ & $360(10.17)$ & $551(15.60)$ & $3534(18.22)$ \\
\hline Total** & $5725(29.5 I)$ & $4044(20.85)$ & $935(4.82)$ & $2520(13.0)$ & $1746(9.00)$ & $1736(8.94)$ & $2693(13.88)$ & $19399(100)$ \\
\hline
\end{tabular}

*P-value $>0.10$

**P-value $<0.005$

From scientific publications throughout the period studied (1994-2003), the vast majority of South African publications came from the field of Clinical Science (29.5 I\%). Plant and Animal Science, Physics and Engineering 20.85\%, $13.80 \%$ and $13 \%$ respectively. The other disciplinary fields, in order of percentage contribution, were Environmental science and Ecology (9.00\%), Chemistry (8.94\%), and Biology and Biochemistry (4.82\%). All the institutions made the highest contribution in clinical sciences except UP (14.55\%) in comparison to other fields of study. Notable differences were found with respect to the contribution made by individual institutions to the different fields of study. University of Pretoria, for example contributed heavily to plant and animal science (37.31\%) and Physics (15.64\%). University of Wits on the other hand, has got the highest publication share in Clinical medicine (42.90\%). University of Cape Town and Natal were strong in the fields of Clinical medicine (26.5 I\%) and Engineering (20.52\%). 


\subsection{Evaluating the performance of South African journals}

Table 3 indicates the performance of South African journals, according to total number of citations per article and impact factor. Despite the fact that the SA journal of Geology was ranked first, due to the high impact factor, it was observed that the South African Medical Journal (SAMJ) had the highest number of citations - 206I from 62 articles, followed by the South African journal of science (S AFR J SCl) - 1397 citations from 89 papers.

Table 3 South African journals in JCR: 2003 indicators

\begin{tabular}{|c|c|c|c|c|c|c|c|}
\hline Rank & Abbreviated Journal Title & Category & Total Articles & Total Cites & $\begin{array}{l}\text { Impact } \\
\text { Factor }\end{array}$ & $\begin{array}{c}\text { Immediacy } \\
\text { Index }\end{array}$ & $\begin{array}{c}\text { Cited } \\
\text { Half life }\end{array}$ \\
\hline I & SA J OF GEOLOGY & Geology & 6 & 438 & 1.021 & 0.333 & 7.7 \\
\hline 2 & SAMJ & Medicine & 62 & 2061 & 0.989 & 0.532 & $>10.0$ \\
\hline 3 & SA J OF SCIENCE & M.D sciences & 89 & 1397 & 0.930 & 0.124 & 9.8 \\
\hline 4 & WATER SA & Water resource & 69 & 490 & 0.600 & 0.174 & 7.2 \\
\hline 5 & AFRICAN ENTOMOL & Entomology & 39 & 108 & 0.577 & 0.000 & 5.0 \\
\hline 6 & J OF VETERINARY RES. & Veterinary Sci & 29 & 675 & 0.548 & 0.034 & $>10.0$ \\
\hline 7 & SA J OF BOTANY & Plant sciences & 49 & 445 & 0.462 & 0.469 & 10.0 \\
\hline 8 & AFRICAN ZOOLOGY & Zoology & 37 & 39 & 0.393 & 0.027 & 9.6 \\
\hline 9 & SA J OF WILDLIFE & Zoology & 19 & 232 & 0.341 & 0.000 & $>10.0$ \\
\hline 10 & BOTHALIA & Plant sciences & 15 & 286 & 0.281 & 0.067 & $>10.0$ \\
\hline 11 & J VETERINARY ASSOC. & Veterinary Sci.0 & 16 & 380 & 0.265 & 0.000 & $>10.0$ \\
\hline 12 & SA J OF CHEMISTRY & Chemistry & 12 & 120 & 0.240 & 0.167 & 8.8 \\
\hline 13 & OSTRICH & Ornithology & - & 321 & 0.187 & - & $>10.0$ \\
\hline 14 & SA J OF ANIMAL SCI & Animal Sci. & 17 & 163 & 0.143 & 0.059 & 9.6 \\
\hline 15 & SA J OF SURGERY & Surgery & 17 & 128 & 0.119 & 0.000 & 9.9 \\
\hline 16 & J S AFR I MINING AND METALLOGY & Metallurgy & 53 & 94 & 0.061 & 0.057 & $>10.0$ \\
\hline 17 & SA J OF MARINE SCI & Marine Biol. & - & 915 & 0 & 0.89 & $>10.0$ \\
\hline \multirow[t]{2}{*}{18} & AFRICAN J MARINE SC. & Marine Biol. & 49 & 58 & - & 1.18 & - \\
\hline & TOTAL & & 578 & 8350 & & & \\
\hline
\end{tabular}

Distribution of papers by journal impact showed that only one journal, SA J OF GEOLOGY, had an impact factor above one. Thirty three percent (33.30\%) of the journals had an impact factor ranging between $0.5-1.0 ; 40 \%$ between 0.2 0.5 and $16.70 \%$ had an impact factor below 0.2 .

Based on the South African journals in the JCR (Table 2), Pearson's correlation coefficient was used to investigate the association among productivity, citation frequency, and impact factor and cited half-life of South African main journals. A one-tailed test was used and it was carried out at the $5 \%$ and $1 \%$ levels of significance.

Statistical analysis regarding the association between journal productivity and citation frequency yielded a Pearson's correlation coefficient of 0.610 with a P-value of 0.010 ; analysis of the citation frequency and impact factor revealed a correlation coefficient of 0.768 with a P-value of $0.00 \mathrm{I}$; analysis of citation frequency and immediacy index revealed a correlation coefficient of 0.596 with a P-value of 0.012 and analysis of impact factor and immediacy index showed a correlation coefficient 0.636 with a P-value of 0.007 .

These results indicate that for South African journals, with $95 \%$ confidence interval (P-value $<0.05$ ), there is a significant correlation between journal productivity and citation frequency, and between citation frequency and immediacy index.

Table 4 Pearson's correlation coefficient matrix (journal variables)

\begin{tabular}{lccccc}
\hline \multicolumn{1}{c}{ Correlations matrix } & Total no. Articles & Total no. Cites & Impact Factor & Immediacy Index & Cited Half-life \\
\hline Total Articles & 1.000 & & & & \\
Total Cites & $0.610^{*}$ & 1.000 & & & \\
Impact Factor & 0.435 & $0.768^{* *}$ & 1.000 & 1.000 & \\
Immediacy Index & 0.319 & $0.596^{*}$ & $0.636 * *$ & -0.205 & 1.000 \\
Cited Half-life & -0.012 & 0.114 & -0.349 & & \\
\hline
\end{tabular}

* Correlation is significant at the p-value $<0.05$ level (1-tailed)

$* *$ Correlation is significant at the p-value $<0.01$ level ( 1 -tailed) 
Further analysis of the results showed that there is no significant correlation at $95 \%$ confidence interval between citation frequency and cited half-life ( $\mathrm{p}$-value 0.349 ), between impact factor and cited half-life ( $\mathrm{p}$-value $0 . \mathrm{III}$ ) or between immediacy index and cited half-life ( $p$-value $0.24 \mathrm{I}$ ). It was also demonstrated that the correlation between journal productivity and cited half-life was not significant at $95 \%$ confidence interval. This suggests that more productive journals usually publish papers of a higher quality in terms of citation frequency and impact factor.

\subsection{A relative comparison of the research- oriented universities of South Africa}

The trend analysis in Figure I depicted that the relative citation impact of both the University of Pretoria (UP) and University of the Witwatersrand (WITS) suffered negative growth during the 9-year period. UP demonstrated further periods of decline. The relative citations' share for UP fell from I.93 in 1994 - 1999 to less than $80 \%$ in $1999-2003(0.37)$, while the relative citations' share for WITS decreased by $49 \%$ during the same period, from I.42 in I $994-1998$ to 0.73 in 1998-2002, and then started to increase by $16 \%$ in 1999-2003. There was not much fluctuation in the percentage share in the relative citation impact of the University of Cape Town (UCT). The University of Stellenbosch (STELL) was noted to have had the highest percentage increase during this period (I80\%), followed by the University of Natal (UN) with an increase of $22 \%$. Both universities (STELL and UN) showed a continuous increase in the relative citation impact from 1994 to 2003.

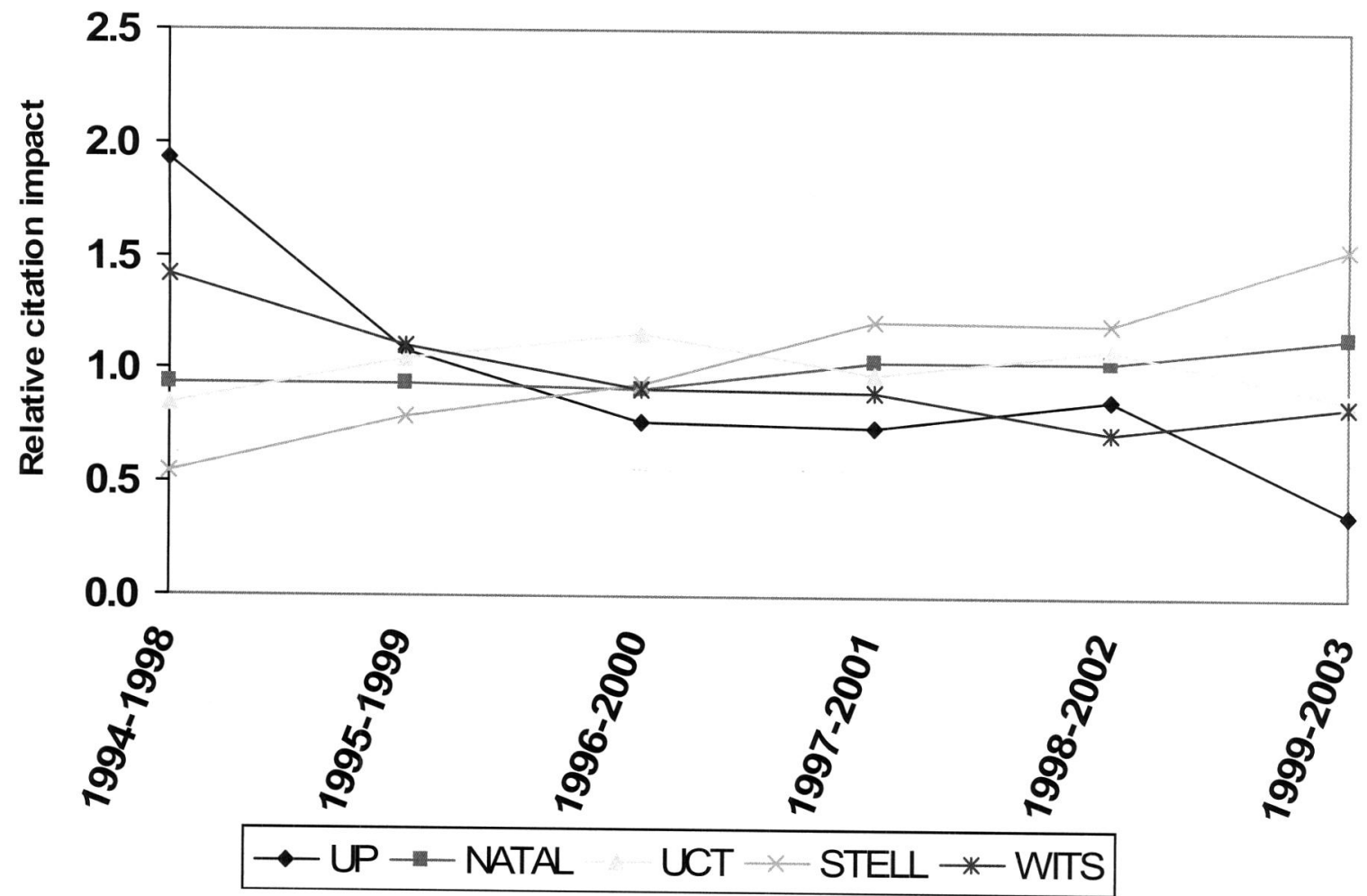

Figure 1 Relative citations for South Africa's most productive university (1994-2003)

\section{Conclusion}

Given the fact that citation indicator is calculated as the average citation rate of all articles in a given field, in this paper comparison has been made among the top South African authors, major South African journals and among most productive institutions. The performance of South African scientists were measured using cited per paper perspectives. The result showed that the four top ranked authors representing $40.80 \%$ of the total count are: Bilic N (I6.40), Michael JP (6.36), Sacht C (6.00), and marques-HM (4.60). From the total 1076 citations counted, it was found that 572 or $53.20 \%$ citations belong to Chemistry, 267 or $24.80 \%$ belong to Physics, and 72 or \&.00\% belong to Geology.

This Bibliometric and comparative analysis of the productivity of the five research universities, in terms of their research output, illustrates the relative strengths and weaknesses of each university. The University of Pretoria had the lead in publication for the last nine years followed by University of Cape Town. But the second half of 2003 showed that in terms of the productivity of articles per institution changed quite markedly. University of Cape Town took the lead with 5198 papers followed by University of Pretoria 3849. University of Stelenbosch had 3659 papers and Wits 3534 and the last position was that of University of Natal with 3159 papers. 
This study also further revealed that out of the 18 South African journals indexed in JCR, only the South African Journal of Geology (SA J OF GEOLOGY), had impact factor above one. Of the remaining journals, $30 \%$ have an impact factor ranging between $0.5-1.0$ and $40 \%$ between 0.2 - 0.5 These results are not satisfactory, as more than $40 \%$ of all the journals in the JCR have an impact factor greater than one (Pouris 2004), indicating that international journals have a higher impact factor. The association between productivity and citation frequency, and between citation frequency and immediacy index have been proved to be positive using the appropriate statistical Pearson's correlation coefficient at the $\mathrm{p}$-value $<0.05$. In other words, journals with high productivity receive more citations and more cited journals attain high immediacy index.

The activity of institutions against their relative citation impact for the time period 1994- 2003, point out that STELL and Natal marked the highest percentage increase by $180 \%$ and $22 \%$ respectively. The most plausible reason that citation impact was higher in STELL than that of UP might be that the authors from STELL collaborated more internationally than did the authors from other South African universities. This caused the papers to be cited higher than those papers for which their authors collaborated nationally. Both the university of Pretoria (UP) and University of Witwatersrand (WITS) suffered from negative growth during the same 9-year period. The percentage increase or decrease of university of Cape Town's (UCT) relative citation impact activity was not as conspicuous. However, individual university still shows strengths in various specific fields.

\section{References}

Christine, L. Borgman \& Jonathan, F. (2002). Scholarly communication and Bibiliometrics. Annual review of Information Science and Technology, 36: I-2.

Egge, L., Rousseau, R \& Van Hoydoonk, G. (2000). Methods for accrediting publications to authors or countries: Consequences for evaluation studies. Journal of the American Society for Information Science, 5I, I45-I57.

Fazel, S., \& Danesh, J. ( I995). Bah'a'l scholarship: an examination by citation analysis, Bah'a'l studies Review, 5(I), I3-26.

Moed, H., Burger, W., Frankfort, J. \& Van Raan, A (1985). The use of bibliometrics data for the Measurement of university research performance. Research Policy, 14, 131 - 149.

Osareh F., (1996). Bibliometrics, citation analysis and co-citation analysis: a review of literature I. Libra, 46, (4): I48-I58.

Pouris, A. (2004). An assessment of the impact and visibility of South Africa journals. Scientmetrics,62, (2): 213-222.

Roche,T.\& Smith,D.( 1978). Frequency of Citations as Criterion for the Rankings of Departments, Journals, and Individuals. Sociological Inquiry, 48, (I): 49-57.

Sen, Subir K. \& Chatterjee, Sunil Jumar. (1990). An introduction to researches in bibliometrics Part I. laslic Bulletin, 35 (3) 1990.

Wilson, C S \& Pittman, S. (2000). Assessments of Outputs: Quantity and quality of cancer research publications in New South Wales from 1994 to 1998. Sydney: The University of New South Wales, School of Information Systems, Technology and management 